Aim Our aim was to develop a range of bereavement support options for people to access in a hope to reach out to more people. Our aim was to increase the number of people receiving support from our service by $30 \%$ over a two-year period.

Method Over a two-year period we have developed a broader range of bereavement support services that has scope to encompass individual ways of grieving. These include the traditional one-to-one and telephone support as well as innovative support systems such as a bereavement online support group, monthly bereavement café, Make, Do and Mend, bereavement craft groups as well as offering advice and support sessions at the local library on a weekly basis.

Results We have now established a broader range of bereavement support services and are delighted to be supporting substantially more people. In May 2017 our service caseload for people accessing the service was 96 and by May 2019 this rose to 250 which confirms a $160 \%$ increase in support being provided.

\section{P-249 ENTERING A PERSON'S WORLD RATHER THAN EXPECTING THEM TO ENTER OURS WHEN ADDRESSING PALLIATIVE CARE}

Liz Mathews. Ashgate Hospicecare, Chesterfield, UK

\subsection{6/bmjspcare-2019-HUKNC.271}

Background National and local research studies highlight the negative impact of social isolation, especially in remote areas of high economic and social deprivation (Marmot, 2010). Vulnerable groups e.g. the terminally ill, carers and the bereaved cannot always access mainstream support networks (Steptoe et al., 2013) and can benefit more from accessible, culturally appropriate and varied support supplied within resourceful bereavement hubs in their local community (Social isolation: annual report of the Director Of Public Health For Wirral, 2012-2013).

Aims To develop multi-disciplinary bereavement hubs within isolated communities that provide tailor-made palliative care for pre/post bereavement. This support will embrace cultural diversity, encouraging self-sustaining provision, empowerment and resilience for terminally ill patients and their carers, friends and family, particularly focussing on the more vulnerable in society e.g. young carers. The project aims to lessen social isolation, increase social capital, and address the public health Five Ways To Wellbeing module.

Methods Review literature. Research local/national need. Feedback analysis. Internal consultation. Consultation with relevant local organisations. Funding applications. Secure premises. Recruit and train specialist hub volunteers to provide practical, spiritual and social support. Liaise with other agencies to collaborate. Assessment and personal goal planning. Continuous service review and evaluation, SystmOne reports of service, Core outcomes and individual evaluation questionnaires.

Results Increased coping skills, wellbeing and mental health measured by Core 34 psychological assessment. Greater social activity and increased peer support verified by group activity registers and regular evaluation. Increased referrals and access to service for isolated young carers. Improved multi-agency working. 36 volunteers trained to offer model of support. Increased education regarding self-care achieved by personal goal planning.
Conclusion Evaluation of the pilot hub showed substantial increase in social activity, peer support, resilience and access to local provision aided by increased multi-agency working. It is beneficial for service users and cost-effective for hospice provision. Also, we saw additional coping strategies and autonomy within families, resulting in an improvement in wellbeing.

\section{P-250 DEVELOPING A SUCCESSFUL BEREAVEMENT DROP-IN GROUP}

Tracey Addy, Helen Brown. Kirkwood Hospice, Huddersfield, UK

10.1136/bmjspcare-2019-HUKNC.272

Kirkwood's Bereavement Drop-in has evolved in recent years to its current successful model. Held every two weeks, on average 45 people attend. The Drop-in has been effective, in part due to its informal and relaxed feel. It is arranged in a 'café'-like style which gives us the ability to split people into smaller groups to help people feel more at ease and less intimidated. Although the Drop-in may feel informal, each session is structured and is set around 'themes'. An example might be 'adjustment and change', 'Making sense of my grief' etc.

Themes are discussed with a volunteer support worker or core staff member available to 'steer' the conversation. Peer support is very evident where members feel able to share personal stories - which are obviously encouraged. Halfway through the session, the group is split in order to offer a larger 'structured therapy group'. This group is facilitated by a core team counsellor and a volunteer counsellor.

In an attempt to manage numbers and to encourage people who are newly bereaved we set up a 'new to service' group. This is specifically for people who are newly bereaved or have had a more recent bereavement. It was evident that these people are clearly at a different 'stage' of grieving and they felt intimidated by the large group - who were clearly 'further on' in their grieving process. We offer five sessions in this group as a 'holding' and 'normalising' support.

Feedback for the drop-in session has been positive, and has been an excellent way of engaging the local bereaved community. There is future scope to expand the drop-in event to address isolation and loneliness. Currently, the possibility of an outreach service is being scoped, in order to reach further areas in Kirklees which could possibly involve other members of the hospice multidisciplinary team such as social workers.

\section{Workplace Business and Culture}

\section{P-251 SOCIAL VALUE - WHY IS MEASURING IMPACT IMPORTANT TO HOSPICES?}

Declan Carroll. Peace Hospice Care, Watford, UK

\subsection{6/bmjspcare-2019-HUKNC.273}

Background Commissioners of public services should already take account of evidence impact where appropriate as part of their evaluation when commissioning services. We believe that we should evidence our impact and value for money and be in a stronger position to deliver more to our community i.e. 
demonstrate our impact in monetary terms, how much value we bring for the money we receive.

Aim Establish and deliver implementation of an impact-reporting framework -identifying outcomes, their measurement and value. This project involved a predictive social value analysis that undertook a representative example of hospice activity upon which to base later monitoring.

Methods Independent company, Kingston Smith, commissioned to carry out relevant research. Mapped out plan for staff, volunteer, patient, relative and stakeholder engagement events, focus groups, surveys and telephone interviews. March 2019, report produced including end of year financial spend to calculate investment, determine impact, set up calculation model to track social value created by the hospice going forward.

Results Total value of impact captured within the scope of the study. Total value that is attributable to the hospice discarding value that is created by influences outside their activity. Return on investment identified - representing social value. Final report to the Board in July 2019 highlights the detailed calculations, but importantly identifies the range of outcomes experienced by stakeholder groups. The report details the context in which outcomes are created and how impact wholly attributable to the hospice is derived including how outcomes have been valued. A sensitivity analysis will test any remaining assumptions and include a range of ratios according to the variables.

Conclusions The full extent of this work will be realised over the coming year as we embed messaging about the impact of our work and its monetary value and see the response from beneficiaries, funders and the public.

\section{P-252 MOVEMENT WIDE CHANGE AND ORGANISATIONAL INSTITUTIONALISM}

${ }^{1}$ Emma Hodges, ${ }^{2}$ Sue Read. ${ }^{1}$ St Giles Hospice, Lichfield, UK; ${ }^{2}$ Keele University, Keele, UK

10.1136/bmjspcare-2019-HUKNC.274

Hospices are being challenged by changing demographics. Originating from a response to cancer, hospices have struggled to significantly shift their narrative. This abstract relates to doctoral research exploring hospices' response to dementia from an organisational theoretical lens. The research highlighted a model of institutional change (Greenwood, Suddaby \& Hinings, 2002) which can be applied, beyond dementia, to the challenges hospices currently face.

The model identifies stages of institutional change that potentially take an institutionalised organisational field (e.g. hospices) from their existing narrative through 'de-institutionalisation' to being 're-institutionalised' with a new, compelling narrative. The stages in-between are critical in creating the confidence for organisations to introduce significant change. The research highlights that in response to dementia (and other non-malignant diseases) key stages of institutional change have not taken place - in particular 'technical viability' (Greenwood, Suddaby \& Hinings, 2002; Hodges \& Read, 2018).

Technical viability is what moves thinking from an idea to a fully formed argument that gains moral and practical legitimacy. A case study on institutional change by Greenwood, Suddaby \& Hinings (2002) highlighted a key ingredient being organisational failure. Hospices have not, up until now, failed.
The imperative for change has never been greater not only are the changing demographics challenging hospices so are the economic conditions.

Whatever the future holds for hospices, the theoretical lens of organisational institutionalism adds useful concepts that would help practically. The research in relation to dementia concludes:

- There needs to be a national conversation on the future of hospice care and Hospice UK are doing this;

- There needs to be a review, using institutional change models as to why other 'external jolts' haven't created a significant movement wide shift and;

- There needs to be training on institutional change including understanding the social context in which each hospice operates, being part of a movement, and also the essential need for the technical viability of any proposed models.

\section{P-253 DRIVING IMPROVEMENT WITHIN THE HOSPICE. IMPACT OF THE PATIENT LED ASSESSMENT OF THE CARE ENVIRONMENT (PLACE)}

Michaela Sen, Jan Lessons. Saint Francis Hospice, Romford, UK

\subsection{6/bmjspcare-2019-HUKNC.275}

Background PLACE is an NHS Improvement Initiative which was introduced in 2013. It assesses the quality of an organisation's environment, putting patients' views at the forefront to assess how the environment supports the provision of care. PLACE assesses privacy and dignity, food and hydration, cleanliness and building maintenance. It looks at the extent to which the environment can support the provision of care for those with dementia or those with a disability.

Aim The aim of undertaking PLACE is to provide a snap-shot of how Saint Francis Hospice (SFH) is performing in relation to a variety of non-clinical activities which impact on the person's experience of their care.

Method A Steering Group was established in 2015 to provide leadership and oversee annual implementation of PLACE. Patient assessors are recruited in consultation with clinical teams. NHS Digital (2018) stipulates that 'the number of staff should not exceed the number of patient assessors'. Training for the assessors is provided. PLACE is undertaken using specified criteria. Scorecards are completed and agreed by the assessors. Data collected is inputted into a central NHS Digital database. On receipt of results the Steering Group agree and own an action plan. The outcome of the PLACE assessment is communicated to the organisation. Progress of the action plan is monitored by the Steering Group and reported accordingly.

Results By making relevant changes results have improved year on year.

2018:

Cleanliness: $100 \%$

Food: $95.98 \%$

Organisation food: $93.29 \%$

Ward food: $98.59 \%$

Privacy dignity and wellbeing: $100 \%$

Condition appearance and maintenance: 99.68\%

Dementia: $98.24 \%$

Disability: $97.12 \%$

NHS Digital publish all results to demonstrate how hospices are performing in relation to each other. 